\title{
Environmental sustainability and Energy Efficiency in Historical Buildings: GeoFit Project Implementation in the Case Study of a medieval fortress in Perugia
}

\author{
Jessica Romanelli ${ }^{1}$, Matteo Di Grazia ${ }^{1}$, Cristina Piselli ${ }^{1,2}$, Anna Laura Pisello ${ }^{1,2}$, Franco Cotana ${ }^{1,2}$ \\ ${ }^{1}$ CIRIAF - Interuniversity Research Centre, University of Perugia, Italy \\ ${ }^{2}$ Department of Engineering, University of Perugia, Italy
}

\begin{abstract}
Italian cities are mainly constituted by buildings constructed until the mid- $20^{\text {th }}$ century by pre-industrial construction techniques. A HVAC system for the energy retrofit of historical buildings is evaluated when applied in the case study of Sant'Apollinare. It consists of a ground source heat pump a water tank for thermal energy storage connected to a low-temperature radiant system and air handling unit. The building thermal-energy behavior, typically influenced by thermal inertia in historical buildings, and the novel HVAC system performance interactions are comparatively assessed together with more traditional scenarios. Energy demand decreases by about one third compared to the pre-retrofit situation.
\end{abstract}

\section{Introduction}

While energy and cost efficiency solutions are widely acknowledged in new constructions, a still deep multidisciplinary interaction is required in case of retrofitting of historical building with cultural heritage value to be preserved. Such value typically represents a huge constraint to face during the course of design and construction phases, and therefore tailored low-impact solutions have to be fitted according to case-specific boundary conditions. The case study building was built in the second half of the XIX century as a part of the medieval complex of Sant'Apollinare fortress in Perugia, Italy (Figure 1).

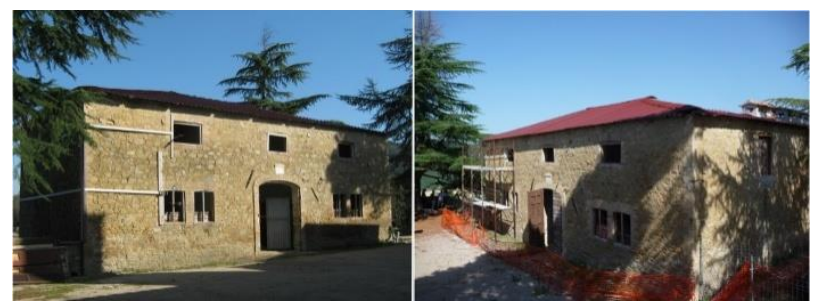

Figure 1: View of the stable of the Sant'Apollinare before renovations.

After the restoration, the building hosts the offices and conference rooms of an International research center dedicated to the development of innovative solutions and technologies for the energy production from biomasses.

The external bearing walls, which are completely preserved, are composed by a mix of local stone and bricks and cork insulations. The historical aspect of the building has determined in the renovation phase the request by the cultural heritage authority, namely "Soprintendenza ai Beni Culturali", not to glue the cork panels to the historical masonry respecting the principle of reversibility, i.e. the principle according to which the intervention must be removed without damaging the original historical masonry preserved. The actual roof is characterized by a wooden structure like the original (Figure 2).

In particular, the building has just won Gold Certification given by GBC Historic Building ${ }^{\mathrm{TM}}$ protocol (Green Building Council Italy,2016). Environmental certifications of buildings represent an important tool for monitoring the impacts of the whole construction process, with the purpose being the development of an environmental consciousness of both occupants and construction stakeholders.
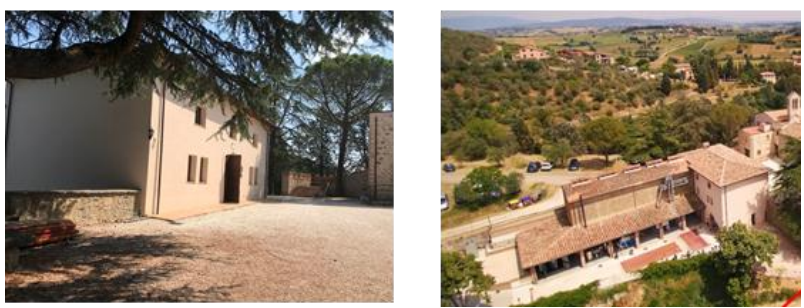

Figure 2: View of the stable of the Sant'Apollinare after renovations.

The GBC Historic Building ${ }^{\text {TM }}$ protocol addresses the issue of the enhancement of the historical and cultural value of the building heritage. This protocol is a tool able to combine and enhance both the sustainability of the construction process and the respect for the high cultural value of the artefacts during the restoration process. The combination of energy efficiency requirements and those of the historical memory drives in particular the choice of materials.

\section{Methods}

In order to evaluate the achievable energy savings, both in terms of economics and environmental impacts related to the retrofit of the gas boiler with a geothermal system, it was conducted a building energy performance simulation in EnergyPlus.

The building thermal energy model was derived directly from the related BIM (Figure 3) model made in the design authoring platform Revit (Autodesk) while the HVAC system was modelled directly into EnergyPlus simulation engine. The data exchange via gbXML schema version 6.0.1 (gbXML 2017) allowed to reduce the amount of 
time needed to redraw the building geometry into another properly CAD software.

For a fair comparison between the simulated performances and the existing building's ones, it was necessary to validate the model firstly based on the thermal zone temperature and secondly on the gas consumption for the entire building. The free-floating validation aimed to verify the building envelope properties and it was conducted in the month of August when the HVAC system was off, whereas the consumption-based validation was related to the operative expenses associated with the HVAC System.

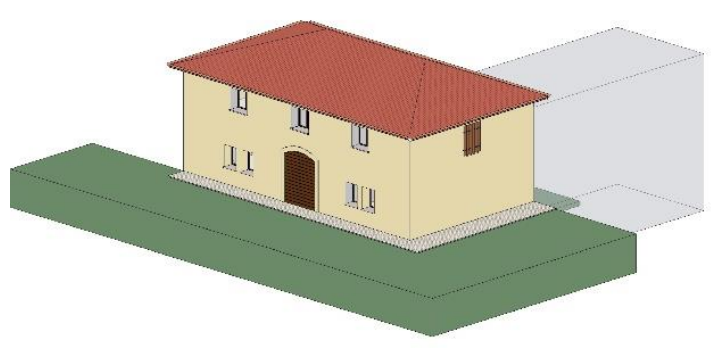

Figure 3: Building information model.

After modelling the new HVAC system with a water to water heat pump and ground heat exchangers we had compared the results obtained in terms of cost-data analysis and in terms of $\mathrm{CO}_{2}$ retained emissions.

\section{Building thermal energy model}

The Ex Stable building of Sant'Apollinare fortress has been recently restored by seismic and energy renovations. The replacement of the windows with low-emissivity glass and seamless external perimeter insulation with 10 $\mathrm{cm}$ thick cork panels have improved the thermal performance of the building which, thanks to the good thermal inertia possessed by the massive masonry, has reduced the heating load and the overall annual energy demand.

The building consists of two floors above ground and a basement. The basement is used as a laboratory for the analysis of biogas samples produced by the biodigester, while the upper floors are intended for offices. The usable area is about $240 \mathrm{~m}^{2}$ for a heated volume of $700 \mathrm{~m}^{3}$. It has been divided into 17 thermal zones, with three unheated rooms that are the technical room for the heating and domestic hot water system (basement), the technical room for the electrical and automation system (basement) and the stairwell.

The various materials making up the building envelope were modelled as layers and then were aggregated into construction layers applied to the analytical surfaces of the model. For transparent surface materials the thermophysical properties entered are thickness, transmittance and reflectance to solar radiation, emissivity and thermal conductivity, as well as values such as transmittance in the visible, useful for calculating the daylight factor (Table 1).The double pane replaced during the energy requalification of the building is low- emissivity type and the filling material of the cavity is constituted by Argon with its relative properties present in the calculation engine. The main thermophysical properties of the opaque surface materials, shown in Table 2 , are the thermal conductivity, the thickness, the density and the specific heat.

Table 1: Thermophysical properties transparent materials.

\begin{tabular}{|c|c|c|c|c|c|c|c|}
\hline Material & $\begin{array}{c}\text { Thickness } \\
{[\mathrm{m}]}\end{array}$ & $\begin{array}{c}\text { Solar } \\
\text { Transmittance }\end{array}$ & $\begin{array}{c}\text { Front Solar } \\
\text { Reflectance }\end{array}$ & $\begin{array}{c}\text { Back Solar } \\
\text { Reflectance }\end{array}$ & $\begin{array}{c}\text { Front Thermal } \\
\text { Emissivity }\end{array}$ & $\begin{array}{c}\text { Back Thermal } \\
\text { Emissivity }\end{array}$ & $\begin{array}{c}\text { Conductivity } \\
{\left[\mathrm{W} / \mathbf{m}^{*} \mathrm{~K}\right]}\end{array}$ \\
\hline 42 & 0.006 & 0.600 & 0.170 & 0.220 & 0.84 & 0.1 & 0.9 \\
\hline 3 & 0.006 & 0.775 & 0.071 & 0.071 & 0.84 & 0.84 & 0.9 \\
\hline
\end{tabular}

Table 2: Thermophysical properties opaque materials.

\begin{tabular}{|c|c|c|c|c|c|}
\hline Material & $\begin{array}{c}\text { Thermal Resistance } \\
{\left[\mathrm{m}^{2} * \mathrm{~K} / \mathrm{W}\right]}\end{array}$ & \begin{tabular}{|c|}
$\begin{array}{c}\text { Thickness } \\
{[\mathrm{m}]}\end{array}$ \\
\end{tabular} & \begin{tabular}{|c|} 
Conductivity \\
{$\left[\mathrm{W} / \mathrm{m}^{*} \mathrm{~K}\right]$} \\
\end{tabular} & \begin{tabular}{|l} 
Density \\
{$\left[\mathrm{kg} / \mathrm{m}^{3}\right]$}
\end{tabular} & $\begin{array}{c}\text { Specific Heat } \\
{\left[\mathbf{J} / \mathbf{k} \mathbf{g}^{*} \mathbf{K}\right]}\end{array}$ \\
\hline BRICK $16 \mathrm{CM}$ & 0.19 & 0.16 & 0.84 & 1700 & 800 \\
\hline BRICK 8 CM & 0.10 & 0.08 & 0.84 & 1700 & 800 \\
\hline CERAMIC FLOOR TILES 14MM & 0.02 & 0.01 & 0.80 & 1700 & 850 \\
\hline CERAMIC TILES PIANELLE 30MM & 0.04 & 0.03 & 0.80 & 1700 & 850 \\
\hline CONCRETE $160010 \mathrm{CM}$ & 0.14 & 0.10 & 0.73 & 1600 & 1000 \\
\hline CONCRETE 24005 CM & 0.03 & 0.05 & 1.91 & 2400 & 1000 \\
\hline CORK PANEL 10CM & 2.44 & 0.10 & 0.04 & 150 & 1670 \\
\hline CORK PANEL 4CM & 0.98 & 0.04 & 0.04 & 150 & 1670 \\
\hline INSULATION RADIANT 4CM & 1.74 & 0.04 & 0.02 & 30 & 1450 \\
\hline INSULATION XPS $10 \mathrm{CM}$ & 2.63 & 0.10 & 0.04 & 30 & 1450 \\
\hline LIMESTONE MORTAR 10MM & 0.14 & 0.10 & 0.70 & 1600 & 840 \\
\hline LIMESTONE MORTAR 13MM & 0.19 & 0.13 & 0.70 & 1600 & 840 \\
\hline LIMESTONE MORTAR 20MM & 0.29 & 0.20 & 0.70 & 1600 & 840 \\
\hline LIMESTONE MORTAR 30MM & 0.43 & 0.30 & 0.70 & 1600 & 840 \\
\hline LMESTONE MORTAR 40MM & 0.06 & 0.04 & 0.70 & 1600 & 840 \\
\hline OSB BOARD & 0.09 & 0.01 & 0.13 & 650 & 1210 \\
\hline PAINTED OAK & 0.18 & 0.04 & 0.19 & 700 & 2390 \\
\hline SCREED LEKA $12 \mathrm{CM}$ & 1.33 & 0.12 & 0.09 & 330 & 1000 \\
\hline SCREED MR81 METAL 6CM & 0.03 & 0.06 & 1.85 & 2000 & 1000 \\
\hline SCREED RENONE 5CM & 0.04 & 0.05 & 1.30 & 2000 & 840 \\
\hline STONE 32CM & 0.09 & 0.32 & 3.49 & 2880 & 840 \\
\hline STONE 39CM & 0.11 & 0.39 & 3.49 & 2880 & 840 \\
\hline STONE $40 \mathrm{CM}$ & 0.11 & 0.40 & 3.49 & 2880 & 840 \\
\hline STONE 44CM & 0.13 & 0.44 & 3.49 & 2880 & 840 \\
\hline STONE $62 \mathrm{CM}$ & 0.18 & 0.62 & 3.49 & 2880 & 840 \\
\hline STONE 72CM & 0.21 & 0.72 & 3.49 & 2880 & 840 \\
\hline STONE 74CM & 0.21 & 0.74 & 3.49 & 2880 & 840 \\
\hline STONE 84CM & 0.24 & 0.84 & 3.49 & 2880 & 840 \\
\hline WEBER CALCE TS & 0.09 & 0.05 & 0.54 & 1500 & 1000 \\
\hline WEBER COTE ACTION & 0.01 & 0.01 & 1.10 & 1900 & 1000 \\
\hline WEBER THERM & 0.71 & 0.03 & 0.04 & 200 & 1000 \\
\hline WOOD FIBRE INSULATION 14CM & 3.68 & 0.14 & 0.04 & 160 & 2100 \\
\hline
\end{tabular}

An example of the views of the building energy model after importing the gbXML file into SketchUp is shown in Figure 4 (a), the final view of the process of assigning constructions to the analytical surfaces is shown in (c), while the boundary conditions are shown in (b) where blue highlights the parts of the building envelope that are exposed to outdoor conditions and therefore subject to solar radiation and wind, while yellow highlights the parts of the structure that are in direct contact with the ground, in (d) the thermal zones are rendered by different colours.
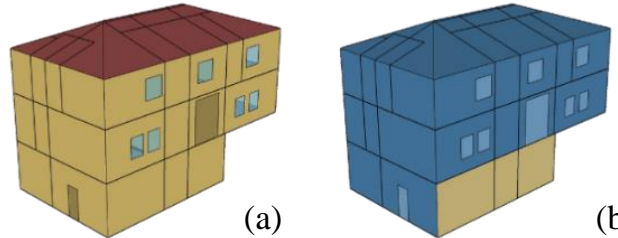

(b)
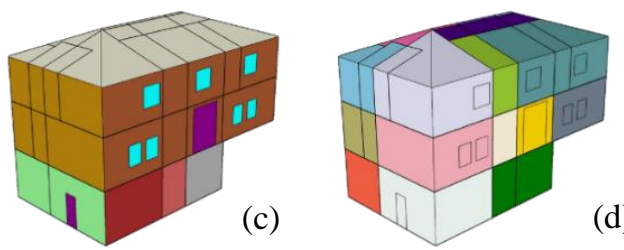

Figure 4: Building energy model. 
The operating profile and internal heat gain due to the presence of people and to the presence of electrical and lighting equipment have been entered through schedules that shows both the values in terms of magnitude and the times at which these contributions are available. Air infiltrations from outside have been included establishing the ASHRAE method of leakages for square meters, (ASHRAE, Handbook Fundamentals 2017). The time of activation of these schedules follows the typical profile of an office building occupation with a peak load by the end of the morning and during mid-afternoon of the weekdays. The heating temperature setpoint is $20^{\circ} \mathrm{C}$ in each thermal zone with the exception of the unheated zones.

\section{Temperature Validation}

For validating the building thermal energy model and verify the correctness of the thermophysical properties of the building envelope, it was necessary to create a specific climatic file for the month of August, since it was the only month in which the external and internal environmental data were available without the HVAC system being operational, and also without the building occupancy. The weather data for the construction of the climatic file were obtained from an on-site weather station, where it was possible to acquire both the dry bulb temperature of the outside air and the relative humidity for the month of August. Subsequently, the climatic file was built using Elements software (Big Ladder Software). On the other hand, the annual thermal energy simulations of the building system were carried out using typical meteorological year (TMY) weather data files.

Then, regarding the thermal zones with available monitored data, it was made a comparison between the simulated temperatures and the internal temperatures recorded by the monitoring system. The comparison returned a good accuracy evaluated by the NMBE (1) and RMSE (2) indices. Their analytical expression is represented in the following equations:

$N M B E=\frac{\sum\left(V_{\text {actual }}-V_{\text {modeled }}\right)}{(N-1) \times \text { mean }\left(V_{\text {actual }}\right)}$
$C V(R M S E)=\frac{\sqrt{\frac{\sum\left(V_{\text {actual }}-V_{\text {modeled }}\right)^{2}}{(N-1)}}}{\text { mean }\left(V_{\text {actual }}\right)}$

Where V states for values while actual and modelled state respectively for monitored and simulated data. These statistical indicators quantify the discrepancies between the simulated outputs and the measured data (ASHRAE Handbook Fundamentals,2017). A simulation model can be considered calibrated if RMSE $<30 \%$ and NMBE $<10 \%$ (ASHRAEGuideline,14-2014). The results of the validation for the thermal zone most exposed to summer weather conditions are reported in Figure 5.

\section{HVAC system model}

In the building, the air conditioning is carried out by a partially recirculating air handling unit (AHU) with inlets into the offices at the first and second floor and outlet into the service rooms. In the AHU there is a cross-flow heat exchanger on the exhaust air and a water heating coil which conditions the mixed air.

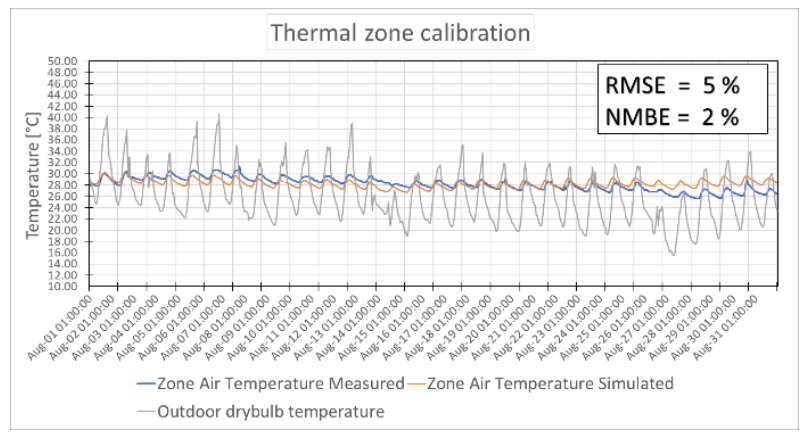

Figure 5: Temperature based validation (August).

The thermal load of the building during the heating period is mainly satisfied by the radiant floors in all the rooms, except for the services where wall radiators are installed. The distribution to the various unit terminals is carried out by a small water storage tank maintained at setpoint temperature by means of a plate heat exchanger between the gas boiler and the tank itself. For the domestic hot water, a2000 litres thermally insulated water tank has been installed in the technical room of the basement but since this study focused on the analysis of the space heating requirement it was not taken into account.

The entire space heating system was modelled via an air loop and three water loops. As requested by EnergyPlus, each system has been divided into two complementary parts: one for the demand side and the other for the supply side (EnergyPlus Plant Application Guide,2018). The three water loops were arranged as follows:

- Hot Water 1 Loop: represents the heat generation part of the system with the gas boiler on the supply side and the plate heat exchanger on the demand side(Figure 6).

- Hot Water 2 Loop: models the intermediate loop between generation and distribution, where the plate heat exchanger provides the heat necessary to mantain the setpoint temperature in the water storage tank (Figure 7).

- Hot Water 3 Loop: represents the final part of the system from the storage tank to the various unit terminals such as radiators, radiant floors and heating coil(Figure 8)

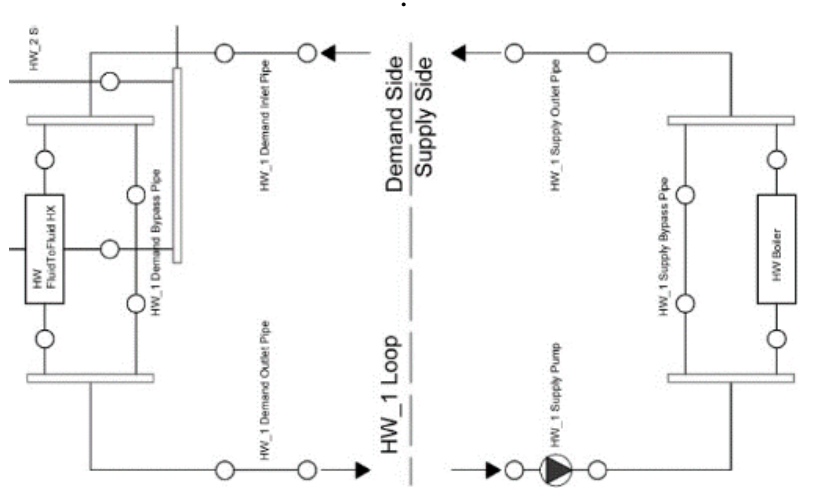

Figure 6: Hot Water 1 Loop. 


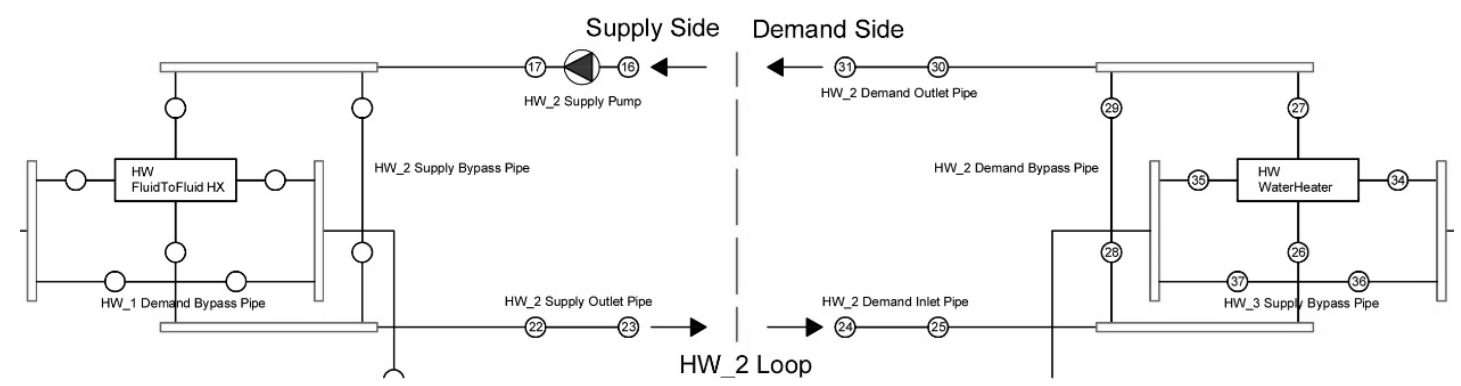

Figure 7: Hot Water 2 Loop.
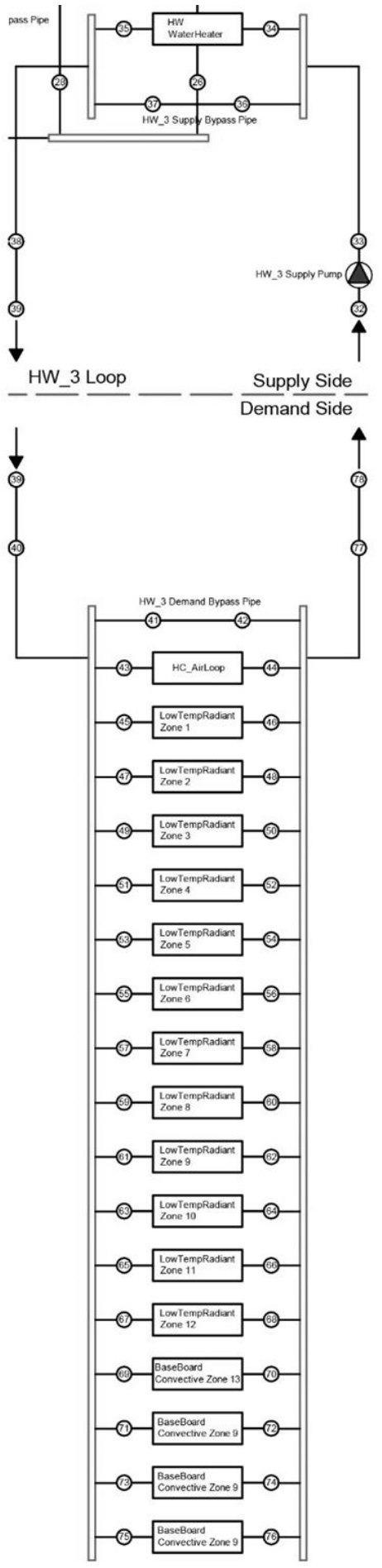

Figure 8: Hot Water 3 Loop.
The setpoint temperature for the heat transfer fluid in the system is $68^{\circ} \mathrm{C}$, which is the temperature required by the AHU heating coil and the wall radiators. The setpoint temperature regarding the radiant floor is considerably lower, reaching $38^{\circ} \mathrm{C}$.

The weekly activation and operation profile of the water system has been described by means of availability schedules, similar to the occupation and occupants metabolic activity profiles, which define when the plant system had to be on or off and whenever cycle on during night time.

The air loop is similar to the hydraulic one. The air unit terminals, consisting of diffusers, are arranged on the demand side and connected to the thermal zones, while supply side, shown in Figure 9, is composed by a half loop, whose elements disposed in series represent the technological equipment in the AHU.

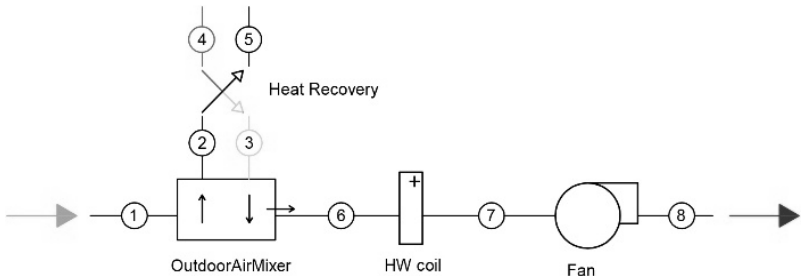

Figure 9: Air loop supply side.

Furthermore, in this loop the weekly operation profile has been detailed by means of schedules, while the presence of the economizer on the outdoor air mixer exhaust path allows free-cooling during the intermediate seasons, whenever temperature and humidity are suitable for contributing in the thermal load reduction.

The thermal load distribution management between the radiant floor and AHU in the thermal zones, where both systems are present, is carried out by assigning a priority to the radiant system. In this case almost all the heating load is satisfied by the radiant floor relegating the main function of supply outdoor fresh air to AHU.

The main HVAC components and their description (EnergyPlus Engineering Reference,2018) are as follows:

1. Boiler Hot Water:represents the gas boiler for which it is possible to insert the efficiency curves and the type of fuel used in this case is natural gas.

2. Heat Exchanger Fluid to Fluid:type of heat exchanger that allows to model a general heat exchanger from fluid to fluid whose power and efficiency are described respectively in equations (3) and (4) below. $\dot{Q}=\varepsilon\left(\dot{\mathrm{m}}_{\mathrm{p}}\right)_{\min }\left(\mathrm{T}_{\text {SupLoop,in }}-\mathrm{T}_{\text {DmdLoop,in }}\right)$ 


$$
\epsilon=\frac{1-\mathrm{e}^{-\mathrm{NTU}\left(1-\mathrm{R}_{\mathrm{C}}\right)}}{\left(1-\mathrm{R}_{\mathrm{C}}\right) \times \mathrm{e}^{-\mathrm{NTU}\left(1-\mathrm{R}_{\mathrm{C}}\right)}}
$$

3. Water Heater Mixed: water storage function and therefore with no capacity of the auxiliary heater. Because of the small volume it is not affected by stratification phenomena (mixed type). The energy balance equation of storage(5) is as follows.

$\mathrm{QVc}_{\mathrm{p}} \frac{\mathrm{dT}}{\mathrm{dt}}=\mathrm{q}_{\mathrm{net}}$

4. Low Temperature Radiant Variable Flow:used to represent the radiant floor and inserted within a type of internal source construction layer to calculate the relative conduction transfer function (CTF)

5. Convective Baseboard Water: represents the radiators present in the service rooms and divide the thermal power emitted into radiant and convective

6. Water Heating Coil:heating coil downstream in the AHU with water controller to vary the flow of hot water depending on thermal load.

7. Air to Air Sensible Heat Exchanger: sensible heat recovery ventilation with a design conditions efficiency of 0.8 .

The results of the simulation for a thermal zone are shown in Figure 10, during the month of February. The trend of the indoor dry-bulb temperature, the radiant temperature and the operating temperature are compared to the outdoor dry bulb temperature during the month of February on hourly timesteps. The zone temperature follows the occupancy and activation profiles with ramps and slope changes. In Figure 11, a widening of the previous graph allows observing in detail the proximity between the operating and radiant temperature with the air temperature, due to both the thermal insulation of the building and the presence of radiative surfaces at higher temperatures. Moreover, during the hours of occupation, the dry-bulb air temperature is higher than the radiant temperature, due to internal heat, gains while it falls below during the closing periods with a thermal drop of about $1.5 \mathrm{~K}$ in two days.

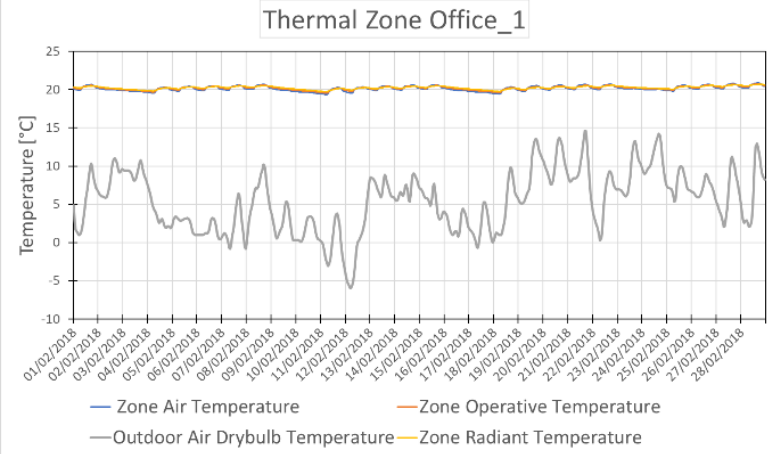

Figure 10: Simulated zone and outdoor air temperatures (February).

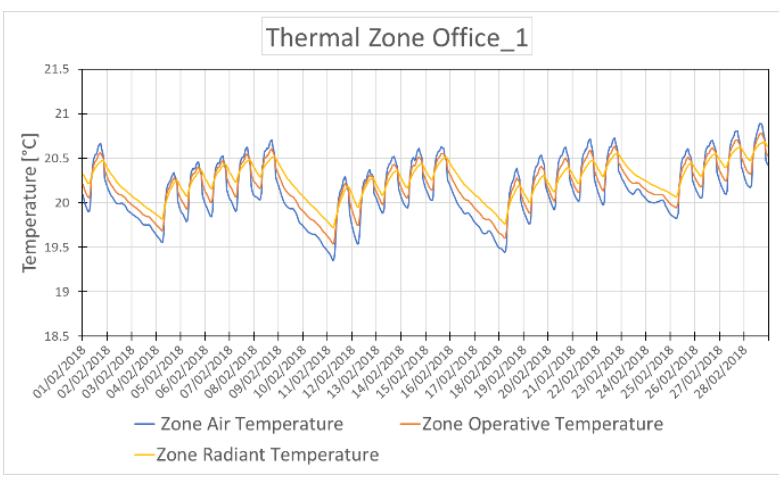

Figure 11: Simulated zone air temperatures (February).

\section{Consumption validation}

The available gas consumption monitored data covered the year following the activation of the system and the newly occupation of the building after renovation.

The consumption recorded in this period, shown in Figure 12 , includes the commissioning and the initial start-up of the HVAC system during December, in which the results of the simulation model deviate significantly.

However, the building performance model behaves acceptably with an RMSE of $3.2 \%$ over a monthly period at hourly timestep. The NBME of $2.7 \%$ is within the limits. Not having at least three consecutive years of consumption monitored data does not permit to define this step as an accurate validation but allows seeing the consistency of the model simulated following the same order of winter consumption magnitude.

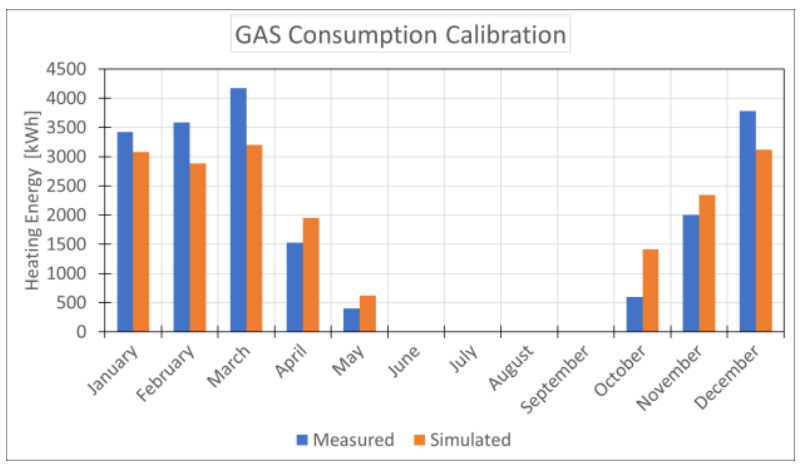

Figure 12: Consumption based validation.

\section{Geothermal system model}

In order to evaluate the savings that could be achieved replacing the gas boiler with a ground source heat pump (GSHP), the energy model was modified by inserting a vapor compression heat pump with a thermal power of 15 $\mathrm{kW}$ and ground source heat exchangers (HEXs). A further hydronic loop has been added to represent the contribution of the two vertical U-tube HEXs with a depth of $70 \mathrm{~m}$ and a diameter equal to $3 \mathrm{~cm}$, as shown in Figure 13.

The mathematical models that can be used within EnergyPlus to simulate the operation of the GSHP consist of two types: the curve-fit model and the parameter estimation-based model (Jin,2002). The former, classified as an equation fit component model by Hamilton and Miller (1990), treats the system as black box by means of four dimensionless curves useful to predict the 
performance of the heat pump in heating and cooling mode. The generalized least square method generates a set of coefficients from the catalogue data which are used in the model to simulate the behaviour of the heat pump (Tang, 2005). The latter, called parameter estimationbased model, form a method between the black box and the deterministic model (Jin and Spitler,2002). A simplified model from basic thermodynamic heat and mass balance equations (Fisher and Rees,2005) is applied to each internal component of the heat pump and to find the required parameter values using manufacturers catalogue data by means of a multi-variable optimization algorithm (Nelder and Mead, 1965). This method is suitable for alternative compressor heat pump but the evaluation of the parameters, when varying the type of compressor of the heat pump, has a huge range of errors in the parameter estimation-based model. As a result, the mathematical model chosen for the heat pump of this paper is based on the equation fit model.

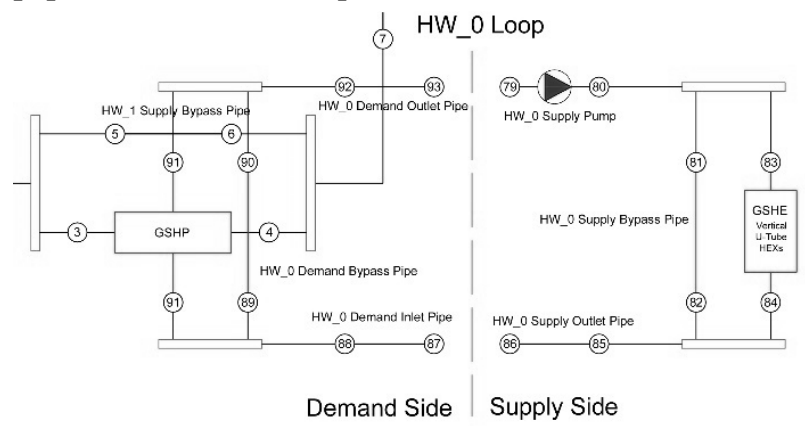

Figure 13: Ground Source Loop.

Kusuda and Achenebach (1965) developed the model used for representing the ground thermal behaviour as function of time and depth which is correlated to the average annual soil surface temperature, the amplitude of the soil temperature changes throughout the year or day of minimum surface temperature and to the thermal diffusivity of the ground. The vertical U-Tube heat exchanger model is based on the work of Eskilson (1987) which solves the problem of heat transmission for borehole by means of a mixed numerical analytical method, determining the response factors under constant initial and boundary conditions over a long timestep. Yavutzturk and Spliter (1999) integrates this model in a short time step considering also the thermal capacity of the ground and grout, the thermal resistance of the pipe and the fluid flow. In this work for determining the thermal response of vertical U-tube HEXs was used as predefined dataset of response factors, based on abovementioned properties and boreholes field configuration. The system configuration of the boreholes field has great influences over the response factors which must be determined before all simulations (Yavuzturk and Spitler,2001).

\section{Results}

The simulation of the GSHP model predicts an annual energy demand equal to 2920 electrical $\mathrm{kWh}$, whose monthly distribution is visible in the Figure 14.

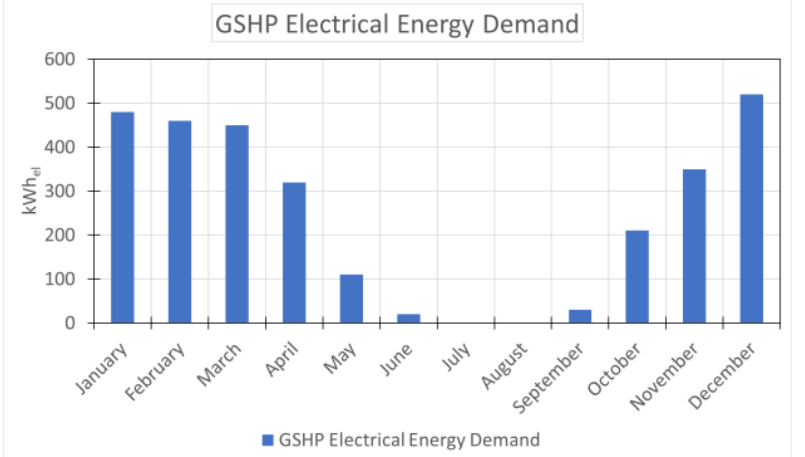

Figure 14: GSHP electrical energy demand.

In terms of source energy demand the comparison between the gas boiler model and the water-to-water heat pump model shows an energy demand for space heating decreased by more than half, as shown in the figure 15 .

In order to estimate the achievable economic savings, according to the energy market prices, it was assigned an average global cost of $0.22 € / \mathrm{kWh}$ to the electricity and an average global cost of $0.8 € / \mathrm{m}^{3}$ for the gas consumption (Figure 16).

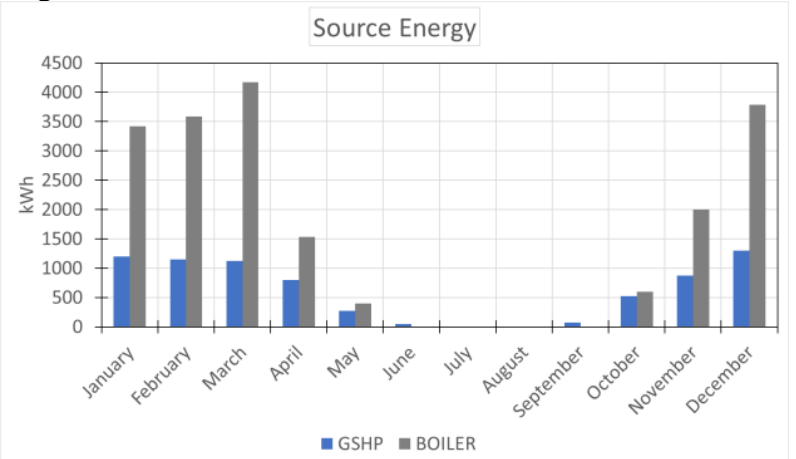

Figure 15: Source energy.

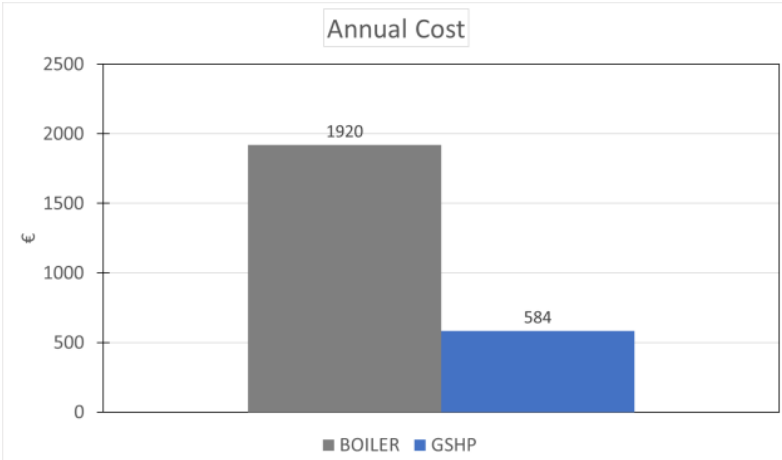

Figure 16: Annual operating cost.

Eventually, considering the current national energy mix, the electricity from the grid is responsible for 0.44 $\mathrm{kg} / \mathrm{kWh}$ of $\mathrm{CO}_{2}$ emissions while the $\mathrm{CO}_{2}$ produced by the combustion of a m $\mathrm{m}^{3}$ of natural gas is equal to $1,89 \mathrm{~kg}$. The saving in terms of $\mathrm{CO}_{2}$ replacing the gas boiler with a GSHP is equal to $3032 \mathrm{~kg} \mathrm{CO}_{2}$ (Figure 17).

\section{Conclusion}

The paper was aimed at investigating novel simulation techniques and procedures specifically tailored for historical buildings, where the implementation of retrofit actions and renewables may be difficult because of architectural constraints. 


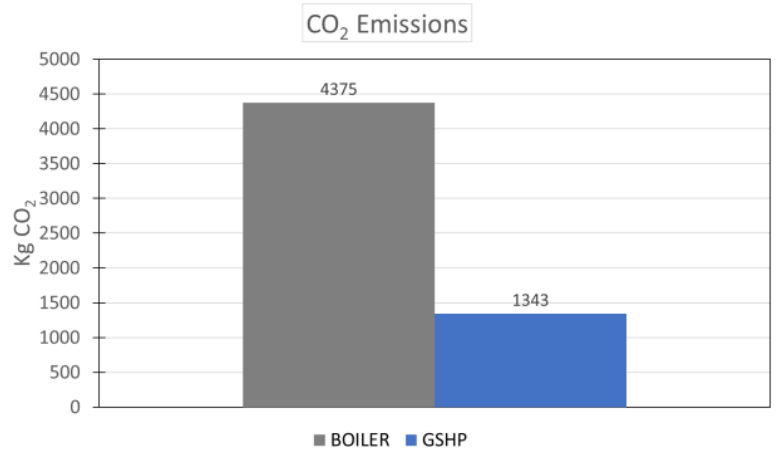

Figure 17: $\mathrm{CO}_{2}$ emission savings.

The building performance simulation following the replacement of the gas boiler with a ground source heat pump gives considerable benefits in terms of source energy savings and $\mathrm{CO}_{2}$ offset while maintaining the same comfort conditions for the occupants, the same settings of temperature control and operation of the HVAC system. In fact, in the retrofitted scenario the source energy demand decreases by about one third compared to the pre-retrofit situation while the $\mathrm{CO}_{2}$ savings reach three quarters of the total. The advantage of the geothermal system is both economic and environmental and is strictly related to the possibility of use the ground as heat source.

\section{Future Developments}

A new hBIM (BIM for historic buildings) platform is proposed, starting from a terrestrial laser scanning combined with digital cameras and with the purpose to consider historical building priorities and energy/structural retrofit actions. Such approach demonstrated its efficacy and will be implemented into this project with the purpose to act as demonstrator of historical building retrofits, by combining energy efficiency, building modern functionality, structural safety and reliability, while not only preserving cultural heritage but also taking advantage of its peculiarities for installing new technologies with low visual impact (geothermal and storage systems).

Very interesting future development consists of a ground source heat pump implementation coupled to innovative "earth baskets" heat exchangers, that will represent an intermediate configuration between fully horizontal and fully vertical systems, with the related variations in terms of cost, drilling depth and total heat exchange potentiality.

\section{Acknowledgements}

This project has received funding from the European Union's Horizon 2020 research and innovation programme under grant agreement No 792210 (GEOFIT)

\section{References}

American Society of Heating, Refrigerating and AirConditioning Engineers (ASHRAE). Measurement of energy, demand, and water savings, (Guideline 14-2014).

American Society of Heating, Refrigerating and AirConditioning Engineers (ASHRAE). (2017). Handbook Fundamentals. Atlanta (GA).
EnergyPlus, Input Output Reference (2018), Version 9.0.US Department of Energy (DoE).

EnergyPlus, Engineering Reference (2018), Version 9.0.Department of Energy (DoE).

EnergyPlus, Plant Application Guide (2018), Version 9.0.Department of Energy (DoE).

Eskilson, P. (1987). Thermal Analysis of Heat Extraction Boreholes. Ph.D. Thesis, Department of Mathematical Physics, University of Lund, Lund, Sweden

Fisher ,D.E. and S.J. Rees (2005) Modeling ground source heat pump systems in a building simulation program (Energyplus). Proceedings from BS2005: Building Simulation.. Montréal (CDN), 23-24 August 2005.

gbXML. http://www.gbxml.org/, version 6.01, January 2017.

Green Building Council (GBC) Historic Building (HB) Protocol, http://www.gbcitalia.org/historic-building.

Hamilton, J.F., and J.L. Miller. 1990. A Simulation Program for Modeling an AirConditioning System. ASHRAE Transactions 96(1), 213-221

Jin, H. and J.D. Spliter (2002). A Parameter Estimation Based Model Of Water-to-Water Heat Pumps for Use in energy Calculation Programs. ASHRAE Transactions 108(1), 3-17.

Jin, H. (2002). Parameter Estimation Based Models of Water Source Heat Pumps. Ph.D. Thesis, Department of Mechanical and Aerospace Engineering, Oklahoma State University,Stillwater, Oklahoma.

Kusuda, T. and P.R. Achenbach(1965). Earth Temperatures and Thermal Diffusivity at Selected Stations in the United States. ASHRAE Transactions 71(1), 61-74.

Nelder, J. A., and R. Mead. 1965. A Simplex Method for Function Minimization.Computer Journal 7(1), 308313

Tang, C.C.,2005. Modeling Packaged Heat Pumps in a Quasi-Steady State Energy Simulation Program.Master of Science. Oklahoma: Department of Mechanical and Aerospace Engineering, Oklahoma State University

Yavuzturk, C. and J.D. Spitler (2001). Field Validation of a Short Time-Step Model for Vertical Ground Loop Heat Exchangers. ASHRAE Transactions 107(1), 617-625.

Yavuzturk, C. and J.D. Spitler (1999). A Short Time Step Response Factor Model for Vertical Ground Loop Heat Exchangers. ASHRAE Transactions 105(2), 475-485. 